\title{
Variation of electrical properties in sepiolite during dehydration
}

\author{
S LOKANATHA and S BHATTACHERJEE* \\ Department of Physics, Indian Institute of Technology, Kharagpur 721 302, India.
}

MS received 21 January 1985; revised 15 April 1985

\begin{abstract}
The dielectric constant $(K)$, loss $(\tan \delta)$ and AC conductivity of a sepiolite sample have been measured as a function of frequency in the range $10^{2}-10^{7} \mathrm{~Hz}$ and in the temperature region $30-400^{\circ} \mathrm{C}$. The $D C$ conductivities of hot pressed pellets were measured in the temperature range $30-550^{\circ} \mathrm{C} . K$ and $\tan \delta$ of these samples decrease with increasing frequency. Results of these measurements have been correlated with the structural transformation accompanying dehydration, making use of DTA, IR and x-ray data. The moderately large value of activation energy $(\sim 2.2 \mathrm{eV})$ in the intrinsic range suggests that the conduction process is most probably associated with ions.
\end{abstract}

Keywords. Sepiolite; dielectric constant and loss; electrical conductivity; dehydration.

\section{Introduction}

Sepiolite is a fibrous chain silicate clay mineral of great commercial value with ideal structural formula $\mathrm{Si}_{12} \mathrm{Mg}_{8} \mathrm{O}_{30}(\mathrm{OH})_{4}\left(\mathrm{OH}_{2}\right)_{4} 8 \mathrm{H}_{2} \mathrm{O}$ for half unit cell. The crystal chemical state of water molecules in this mineral can be classified, beside the hygroscopic, into three distinct groups viz. zeolitic, bound and hydroxyl water designated as $\mathrm{H}_{2} \mathrm{O}, \mathrm{OH}_{2}$ and $\mathrm{OH}$ respectively, which play a dominant role in deciding its physico-chemical properties and dehydration characteristics (Nagata et al 1974). One of the most potential uses of this mineral is as insulating material like asbestos. It is well established that electrical conductivity and dielectric constant are the two most significant parameters in determining the electrical behaviour of a mineral (Keller 1966). However, it appears that no serious attempt has been made to date, to make an in depth study of the electrical properties, especially in relation to dehydration transformation of this potentially useful mineral. Hence, an attempt has been made to study the temperature and frequency variations of the different electrical parameters of a sepiolite sample and to correlate the results with the structural transformation accompanying dehydration, making use of DTA, IR and x-ray data.

\section{Experimental details}

A specimen of sepiolite from Minas de Gador (Spain) was used for the present investigation. The results of chemical and thermal analyses have already been reported (Lokanatha and Bhattacherjee 1985). The chemical data conform to the structural formula $\left(\mathrm{Si}_{11.74} \mathrm{Al}_{0.22} \mathrm{Fe}_{0.04}^{3+}\right)\left(\mathrm{Mg}_{7.07} \mathrm{Fe}_{0.65}^{3+} \mathrm{Ti}_{0.05}\right) \mathrm{O}_{32} \mathrm{Ca}_{0.12}$ for the half unit cell. The DTA

\footnotetext{
* To whom all correspondence must be addressed.
} 
curve shows four broad endotherms around 110-200, 310-420, 450-600 and $800^{\circ} \mathrm{C}$ respectively, followed by an exothermal peak at $830^{\circ} \mathrm{C}$. Sample preparation and measurement of electrical properties were carried out by adopting the same method as reported (Lokanatha and Bhattacherjee 1984b).

\section{Results and discussion}

Results of investigations are illustrated in figures 1,2 and 3. It is seen that in general both dielectric constant $(K)$ and loss $(\tan \delta)$ decrease with frequency, having larger values at lower frequencies (figure 1). The values of $K$ and $\tan \delta$ at $10^{6} \mathrm{~Hz}$ are found to be 5.2 and 0.185 respectively, which are quite comparable with those of other chain silicate minerals like amphiboles and palygorskite (Lokanatha and Bhattacherjee 1984a, b; Mukherjee et al 1978; Vijayasree et al 1976). However, both $K$ and $\tan \delta$ decrease upto $150^{\circ} \mathrm{C}$ and thereafter remain constant upto $250^{\circ} \mathrm{C}$, beyond which both increase again with rise of temperature (figures $2 a$ and $b$ ).

Temperature variations of $\mathrm{AC}$ and $\mathrm{DC}$ conductivities above $200^{\circ} \mathrm{C}$ are shown in figure 3. Variational pattern of $D C$ conductivities can broadly be divided into three main stages. The first stage extends up to $200^{\circ} \mathrm{C}$; the conductivity with a slight initial rise upto $60^{\circ} \mathrm{C}$ falls sharply upto $200^{\circ} \mathrm{C}$, thereafter in the second stage it increases gradually upto

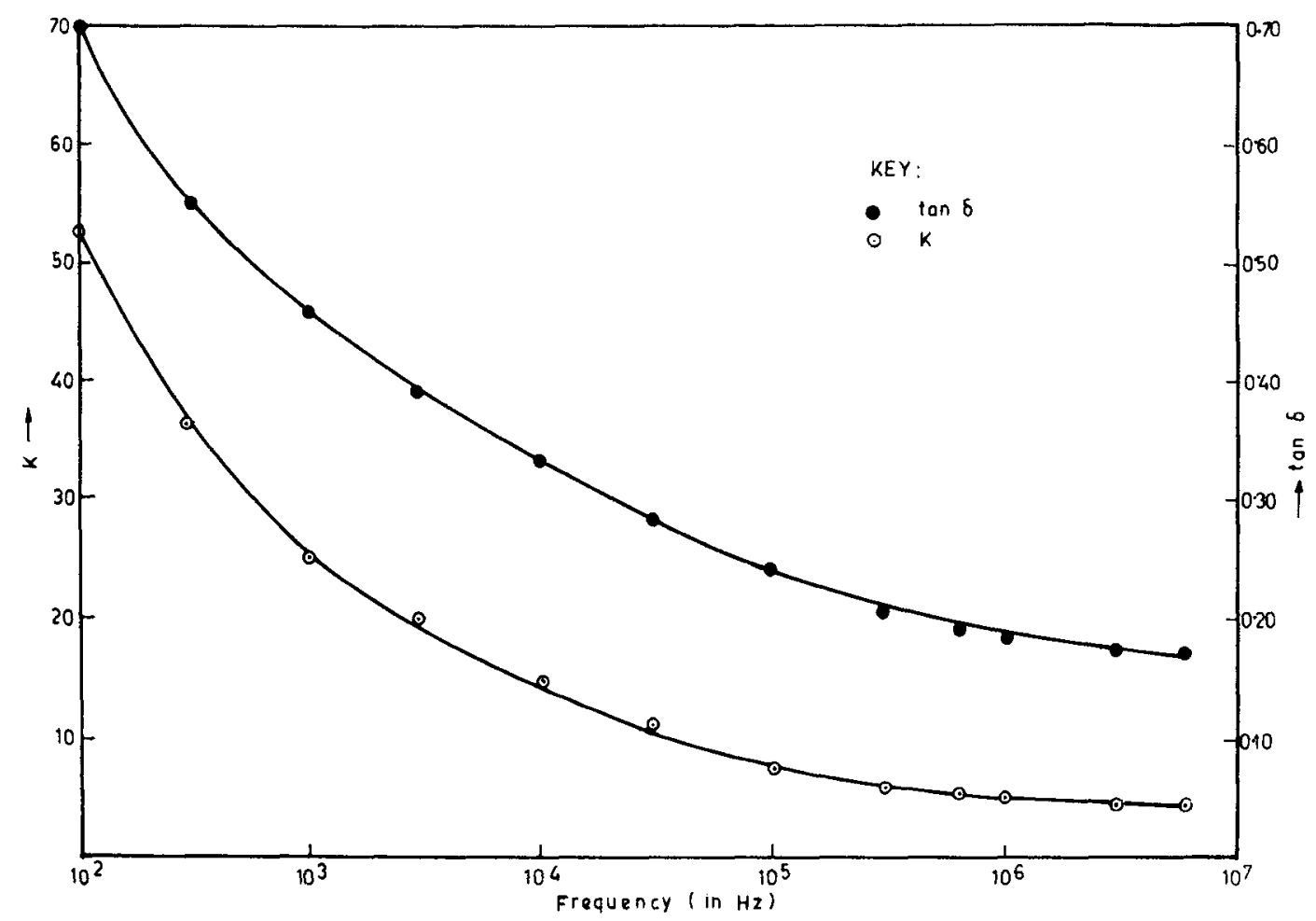

Figure 1. Variation of dielectric constant $(K)$ and loss $(\tan \delta)$ with frequency at room temperature $\left(\sim 30^{\circ} \mathrm{C}\right)$. 

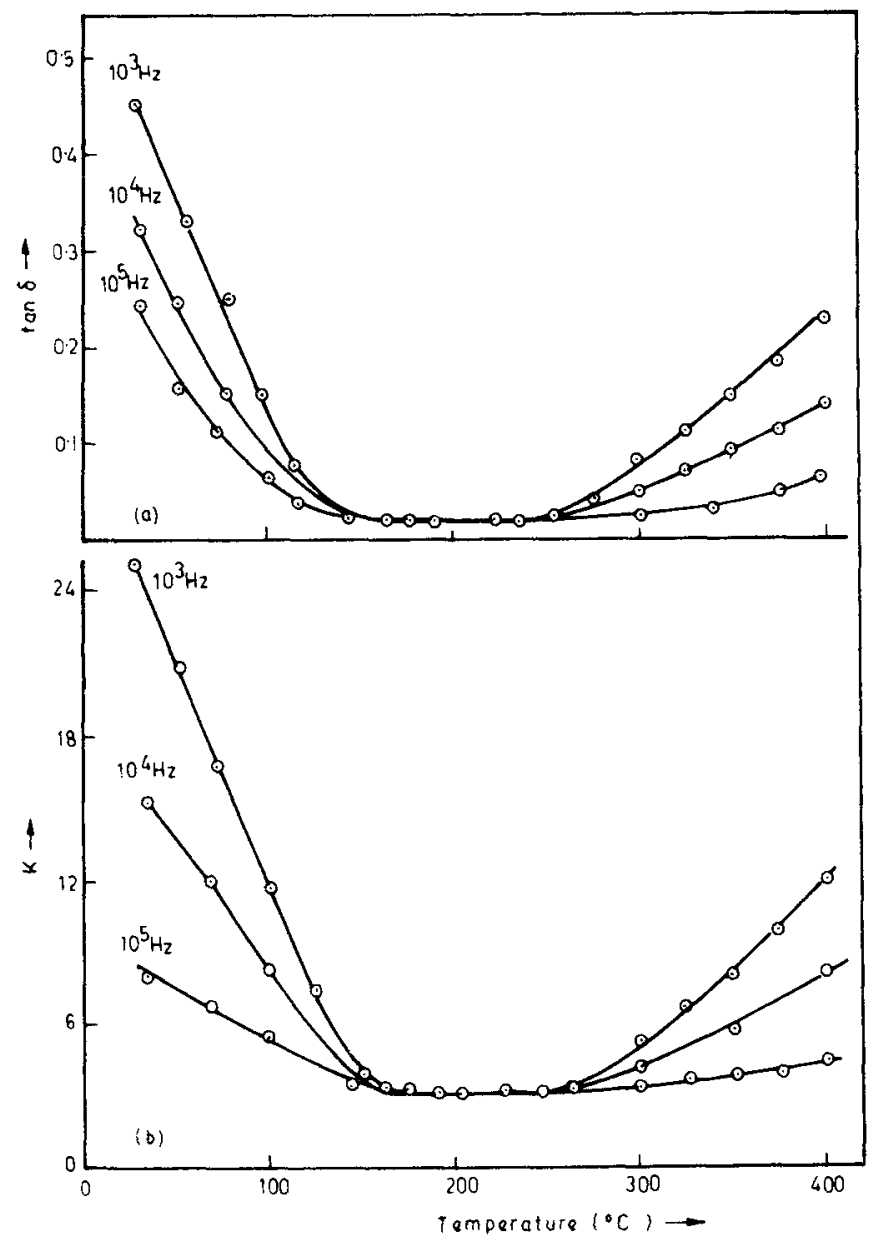

Figure 2. a. Variation of dielectric loss $(\tan \delta)$ with temperature at different frequencies, b. Variation of dielectric constant $(K)$ with temperature at different frequencies.

$380^{\circ} \mathrm{C}$, above which it is found to remain constant upto $450^{\circ} \mathrm{C}$, and then increases sharply with rise of temperature. Since the first stage is associated with the elimination of the loosely bound and randomly distributed adsorbed and zeolitic water around this temperature, as is evidenced by DTA and the cooling curve, and does not yield any useful information on lattice transformation, the corresponding part of the curve has not been reproduced. The variations of $\mathrm{AC}$ conductivities with temperature corresponding to different frequencies follow a more or less similar three stage pattern. However, the AC conductivities at any temperature are found to increase with frequency and are also greater than the corresponding DC due obviously to the contribution of various types of polarization (Lokanatha and Bhattacherjee 1984a, b; Rao and Smakula 1966). Like $\sigma \mathrm{DC}, \sigma \mathrm{AC}$ also increases above $200^{\circ} \mathrm{C}$, the rate of increase however, being higher at lower frequencies when the bound water $\left(\mathrm{OH}_{2}\right)$ starts escaping from the lattice as observed by DTA and IR measurements (Lokanatha and Bhattacherjee 1985; Serna et al 1975; Hayashi et al 1969). 


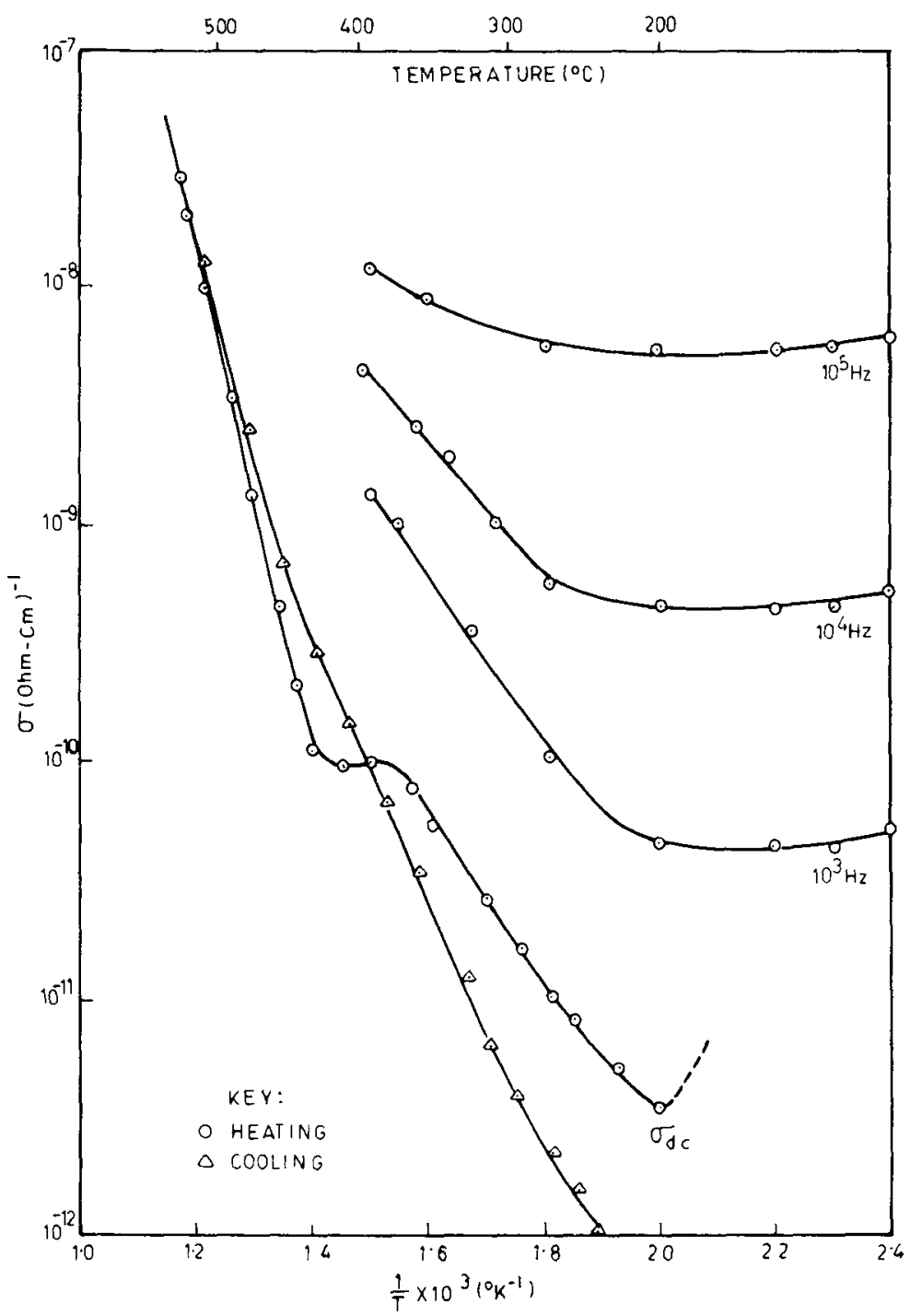

Figure 3. Variation of $A C$ and $D C$ conductivities with inverse temperature.

It is well known that when a solid is placed in an electric field, the movement of charge carriers and their accumulation at the interfaces of the sample and the electrodes, in addition to the various types of polarization, will play a dominant role (Rao and Smakula 1966). In fact, the variation of $K$ and $\tan \delta$ with temperature and frequency will be indicative of the type of polarization present. It is also well established that the different types of water present in sepiolite as mentioned earlier escape at different temperature as revealed by DTA. These water molecules also play a dominant role in controlling the thermal behaviour of the electrical properties especially at lower frequencies.

Consequently the high values of $K$ and $\tan \delta$ at lower frequencies and room temperature can very well be attributed to dipolar and space charge polarizations due 
to the hygroscopic and zeolitic $\left(\mathrm{H}_{2} \mathrm{O}\right)$ water present at this temperature. The rapid fall of $K$ and $\tan \delta$ upto $150^{\circ} \mathrm{C}$ is obviously due to the expulsion of zeolitic water resulting in decrease of dipolar polarization. However, the rise of $K$ and $\tan \delta$ values above $250^{\circ} \mathrm{C}$, particularly at lower frequencies, is most likely due to the space charge polarization arising from various types of impurities and the lattice defects which are invariably present in this sample (Lokanatha and Bhattacherjee 1985).

The DC conductivity curve too, like the $\sigma \mathrm{AC}$, demonstrates the existence of a three stage dehydration process consistent with DTA, x-ray and IR measurements. The first stage which extends upto $200^{\circ} \mathrm{C}$, and is marked by a sharp fall corresponds mainly to the expulsion of the hygroscopic and zeolitic water. The second stage with an initial rise upto $380^{\circ} \mathrm{C}$ followed by a nearly constant region spread over $380-450^{\circ} \mathrm{C}$ is associated with the anhydride phase resulting from removal of half of the bound water $\left(\mathrm{OH}_{2}\right)$ as observed by earlier workers (Nagata et al 1974; Serna et al 1975; Hayashi et al 1969). The second stage corresponds to the second endothermal peak in the DTA curve. The absence of these steps in the cooling curve clearly demonstrate the validity of the reasons attributed to for this type of behaviour. The third step starts from $450^{\circ} \mathrm{C}$ onward and is associated with the true anhydride phase formed by the removal of remaining bound water corresponding to third endothermal peak in the DTA. These observations are quite in conformity with the $\mathrm{x}$-ray, DTA and IR measurements (Hayashi et al 1969).

Consideration of the cooling curve and comparison of the results with those of structurally similar minerals, lead to the conclusion that the increase of DC conductivity in the intrinsic range is due mainly to the increase in mobility of ions. The variation of AC conductivities is connected to the different types of polarization which are responsible for the higher value of $\sigma \mathrm{AC}$ compared to $\sigma \mathrm{DC}$ values at corresponding temperatures (Lokanatha and Bhattacherjee 1984b). This behaviour is consistent with the dielectric measurements. The tendency of $\mathrm{AC}$ conductivities to merge with the $\mathrm{DC}$ conductivities at higher temperature clearly shows that the charge carriers in both the cases are the same in this temperature range. Further, these measurements reveal that the stepwise variations of electrical properties can very well be correlated with the dehydration transformation in this mineral.

\section{Acknowledgement}

The authors express their sincere thanks to Prof. K V Rao and Dr R C Bhuniya for providing the experimental facilities and many helpful discussions.

\section{References}

Hayashi H, Otsuka R and Imai N 1969 Am. Mineral. 531613

Keller G V 1966 Handbook of physical constants (ed.) S P Clark Jr (New York: Geological Society of America) p. 553

Lokanatha S and Bhattacherjee S 1984a J. Mater. Sci. Lett. 3299

Lokanatha S and Bhattacherjee S 1984b Indian J. Pure Appl. Phys. 22719

Lokanatha S and Bhattacherjee S 1985 Z. Kristallogr. (in press)

Mukherjee P S, De A K and Bhattacherjee S 1978 J. Mater. Sci. Lett. 131824

Nagata H, Shimoda S and Sudo T 1974 Clays Clay Miner. 22285

Rao K V and Smakula A J 1966 J. Appl. Phys. 37319

Serna C, Ahlrichs J L and Serratosa J M 1975 Clays Clay Miner. 23452

Vijayasree G, Mukherjee P S and Bhattacherjee S 1976 Indian J. Phys. 501052 